\title{
A selective agraphia of Kana
}

\author{
K. Abe ${ }^{1}$ and R. Yokoyama ${ }^{2}$ \\ ${ }^{1}$ Department of Neurology, Osaka University Medical School, and ${ }^{2}$ Division of Speech \\ Therapy, Kishiwada Tokushukai Hospital, Japan
}

Correspondence to: K. Abe, Department of Neurology, Osaka University Hospital, 2-2 Yamadaoka, Suita City, Osaka 565, Japan

\begin{abstract}
We report a patient who developed selective Kana (phonogram) agraphia following an infarct in the left middle frontal gyrus known as Exner's area. He had well-preserved ability for comprehension, reading, and writing Kanji (ideogram). Kana errors consisted of substitution with another letter while the number of target words was well preserved. It is suggested that a dominant middle frontal gyrus lesion can result in agraphia.
\end{abstract}

Keywords: Agraphia - Exner's area - Kana - Middle frontal gyrus - Writing center

\section{INTRODUCTION}

Writing is a complex function combining linguistic, acoustic, praxic, space-constructional, visual and motor components (Leischner, 1969). Impairment restricted to writing without other linguistic dysfunction is called pure agraphia. We report a patient with selective agraphia of Kana (Japanese phonogram) with perfectly preserved Kanji (ideogram) writing.

\section{CASE REPORT}

The patient was an 81-year-old right-handed retired teacher. No writing difficulty was observed during his education or subsequently. He had had medication for atrial fibrillation since 1980 , but had no difficulty in daily activities. On 6 November 1991, he complained of severe nausea and was admitted to our hospital. On examination he had normal muscle strength, coordinated movements, and cranial nerve and sensory function. He had slight hypotonus in the right arm and leg. He had normal cognitive function except for an impaired ability to write. A computed tomographic (CT) scan demonstrated a reduced attenuation lesion in the left frontal lobe. The lesion was demonstrated more clearly on repeat CT scanning 2 days later. A magnetic resonance image demonstrated an abnormal signal in the left middle frontal gyrus and adjacent white matter (Fig. 1a). A single photon emission tomographic image using ${ }^{123}$ Iiodoamphetamine showed reduced isotope uptake in the same location (Fig. 1b).

He was attentive, cooperative and fully oriented to time and place. Digit span was 6 forward and 5 backward. Recent and remote memory were well preserved. Conversation comprehension, pointing span and syntactic comprehension were well preserved. Spontaneous speech, repetition and object naming were normal. Comprehension of written sentences and reading aloud were accurate. Reading of Kanji and Kana characters was at the same level of competence. Serial seven and copying of a cube were performed well and he was not apraxic (full scale on the Western Aphasia Battery praxis subtest). The parietal lobe tests (right-left orientation, two point discrimination, skin graphesthesia, point localization, finger naming, optokinetic nystagmus, visually guided reaching, stereognosia and spatial ability) were all intact. Double simultaneous stimulations (auditory, tactile and visual) were correctly perceived on both sides.

He made many Kana writing errors in spontaneous writing as well as in dictation, while Kanji writing was perfectly preserved. Kana errors were characterized by substitutions with another letter, but the letter forms were correct. A similar writing disturbance was found with either hand. After writing to dictation, he was often surprised at his performance; however, he could not correct it. The copying of letters was preserved.

To evaluate his ability to transcribe heard words into Kanji and Kana characters, the following test was carried out (Tanaka et al., 1987). Fifty stimulus words having from one up to five syllables were presented orally. The number of target Kana letters corresponded to the number of syllables while the 

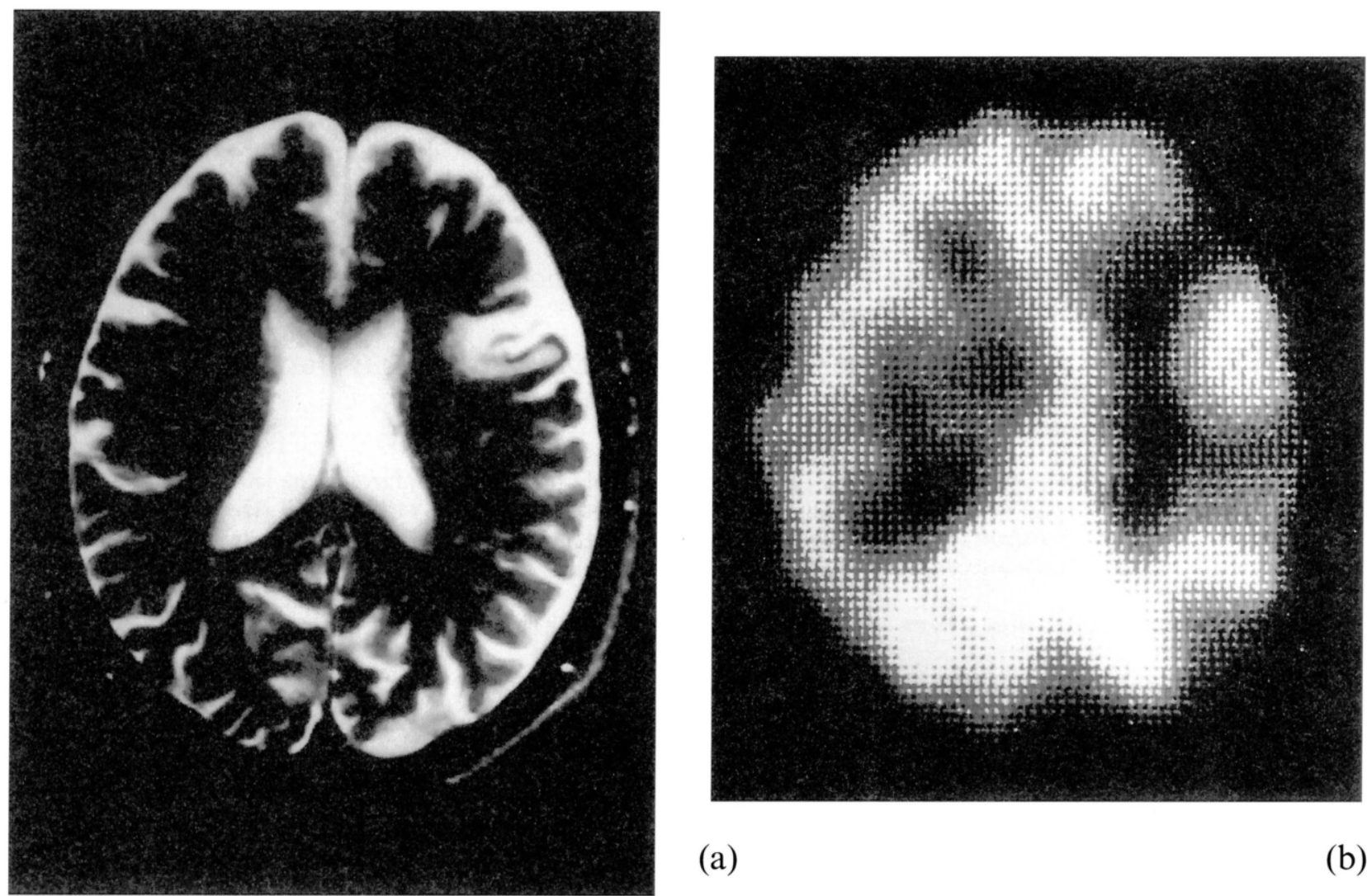

(a)

(b)

FIG. 1. (a) A T2-weighted magnetic resonance image. Imaging was carried out in a 0.5 Tesla superconducting system with spin-echo method, TR/TE $=2500 / 90 \mathrm{~ms}$. A T2 high intensity lesion is seen in the left middle frontal gyrus and adjacent white matter. (b) A single photon emission tomographic image using ${ }^{123}$-iodoamphetamine. Reduced isotope uptake is demonstrated in the left middle frontal gyrus and adjacent white matter.

number of target Kanji letters was one letter for one to three syllables, two letters for four syllables, and two or three letters for five syllables. First, the patient was asked to transcribe dictated words into Kanji, and then into Kana with the right hand. To rule out the effect of short-term verbal memory, the dictated words were always repeated. Even after he had written a dysgraphic sequence, he could always repeat

$$
\begin{aligned}
& l h \text { 尔 } h \text { ' SHI-N-PU-N' } \\
& \text { 新用, SHI-N-BU一N'( newspaper) }
\end{aligned}
$$

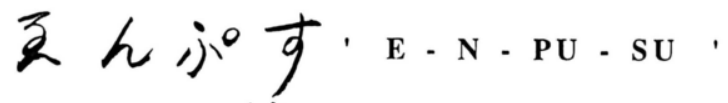

$$
\begin{aligned}
& \text { 捈策， E- N - PI - TSU'（ pencil） }
\end{aligned}
$$

FIG. 2. Examples of the patient's writing from dictation of four syllable words. All Kanji words shown in this figure are correct. The results of Kana writings are as follows (1) "SHI-N-PU-N" is incorrect; it should be "SHI-N-BU-N" (newspaper); (2) "E-N-PU-SU" is incorrect; it should be "E-N-PI-TSU" (pencil). Kana errors were characterized by substitutions with another letter, but letter forms and letter numbers were correct. 
correctly what he should have written. Accordingly, his writing errors did not seem to be caused by a short-term memory problem. An example of the patient's writing of four syllable words is shown in Fig. 2.

\section{DISCUSSION}

Characteristic features of this agraphia were: (1) Kana writing was selectively impaired compared with Kanji; (2) errors in Kana writing consisted of substitutions but the number of Kana letters produced was a good approximation of the number of syllables of the target word; (3) letter forms were well preserved; and (4) the responsible lesion for agraphia was restricted to the dominant middle frontal gyrus, known as Exner's area.

Although agraphia may result from a confusional state (Chedru and Geshwind, 1972), localized brain damage may also cause pure agraphia (Gordinier, 1899; Kinsbourne and Rosenfield, 1974; Aimad et al., 1975; Auerbach and Alexander, 1981). Our patient was attentive and fully oriented with digit span of 6 forward and 5 backward, therefore his writing disturbance suggested localized brain damage. Although impairment of short-term memory may cause dysgraphia, his accurate repetition of presented words, even when he misspelled them, demonstrates his normal short-term memory.

The Japanese script system consists of two different types of letters. Kanji characters are ideograms with roots in China, each of which has one or more meanings and pronunciations. Kana is a syllable in Japanese. All Japanese expressions can be written in Kana, but not in Kanji. Although the processing of Kanji and Kana has been considered to depend on different neural pathways in the central nervous system, a comprehensive model has not yet been determined. Three cases of selective Kana agraphia have been reported. Responsible lesions for these agraphias were a left frontal lesion (Sato et al., 1983), a left parietal lesion (Kimura et al., 1986; Tanaka et al., 1987) and left temporal lesions (Tanaka et al., 1987). However, they also had paraphasia and the responsible lesions were not restricted to a single site. In contrast our patient had a single lesion in the left middle frontal gyrus and did not have other linguistic dysfunctions. Despite the notion that agraphia may result from damage to Exner's area, there have been few clinical descriptions of such patients. This is partly because lesions causing linguistic defects are also likely to cause hemiparesis on the dominant side. Despite this confounding factor, there are a number of cases with pure agraphia involving the dominant middle frontal gyrus (Gordinier, 1899; Cubelli, 1991; Roeltgen, 1993). Cubelli (1991) reported a patient demonstrating a selective deficit for writing vowels after an ischemic infarction in the left frontal subcortical region. Although there is a difference in the writing systems, this case shared a number of common features with the present case and the dysgraphia mainly consisted of paragraphia preserving letter number of the target word. According to the current model of writing and spelling, preserved letter form and word length suggest a preserved graphemic buffer and motor programming. We therefore believe that our patient had impaired graphic output programming resulting from a lesion in the left middle frontal gyrus and adjacent white matter.

\section{REFERENCES}

Aimad G, Devic M, et al. (1975) Agraphia pure (dynamique?) d'origine frontale apropos d'une observation. Revue Neuorologique, 131, 305-512.

Auerbach SH and Alexander MP (1981) Pure agraphia and unilateral optical ataxia associated with a left superior parietal lobule lesion. Journal of Neurology, Neurosurgery and Psychiatry, 44, 430-432.

Chedru F and Geshwind N (1972) Writing disturbances in acute confusional states. Neuropsychologia, 10, 343350:

Cubelli R (1991) A selective deficit for writing vowels in acquired dysgraphia. Nature, 353, 258-260.

Gordinier HC (1899) A case of brain tumor at the base of the second left frontal convolution. American Journal of Medical Sciences, 117, 526-550.

Kimura B, Matsuda K, Kuroiwa Y and Tohgi H (1986) Pure agraphia in the left parietal subcortical infarction. Neurological Medicine, 24, 484-488.

Kinsbourne M and Rosenfield DB (1974) Agraphia selective for written spelling: an experimental case study. Brain and Language, 1, 215-226.

Leischner A (1969) Agraphias. In: Clinical Neurology, Vol. 4 (Eds PJ Vinken and GW Bruyn), pp. 141-180. NorthHolland, Amsterdam.

Roeltgen DP (1993) Agraphia. In: Clinical Neurology, 2nd edn (Eds KM Heilman and E Valenstein), pp. 63-89. Oxford University Press, New York.

Sato M, Yasui N, Suzuki A, Kawamura S, Sayama I and Kobayashi T (1983) Agraphia from the frontal lesion: a case of Moyamoya disease. Brain and Nerve, 35, 11451151.

Tanaka Y, Yamadori A, et al. (1987) Selective Kana agraphia: A case report. Cortex, 23, 679-684. 


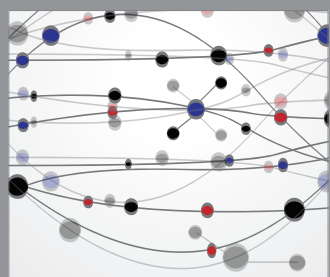

The Scientific World Journal
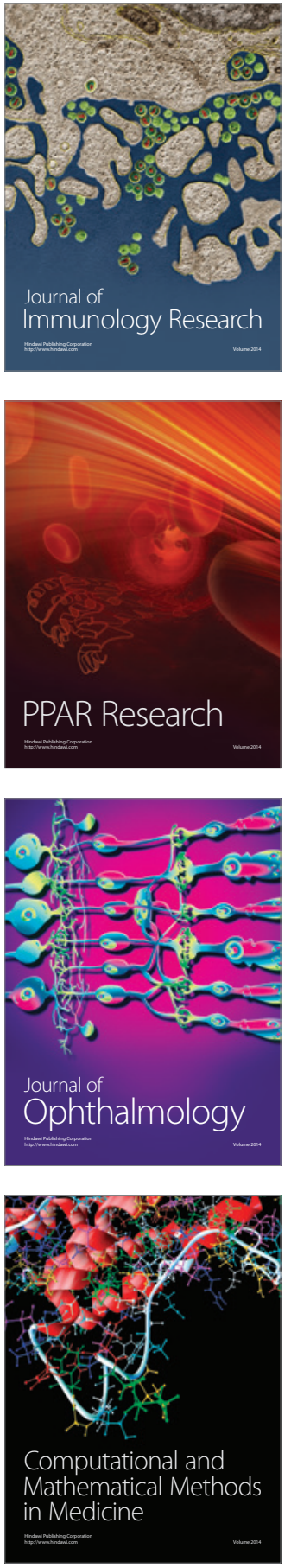

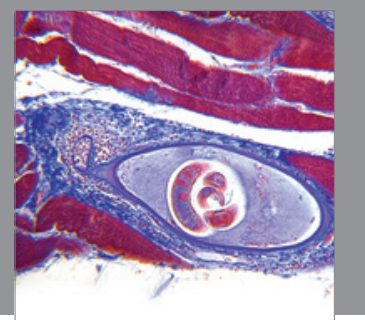

Gastroenterology

Research and Practice
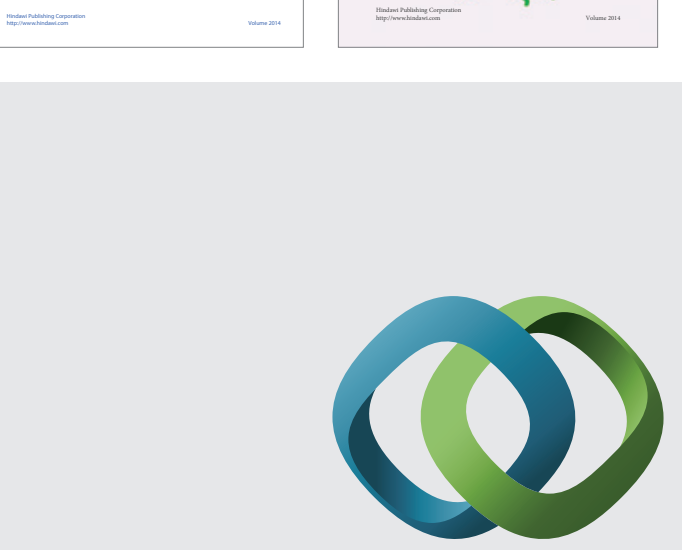

\section{Hindawi}

Submit your manuscripts at

http://www.hindawi.com
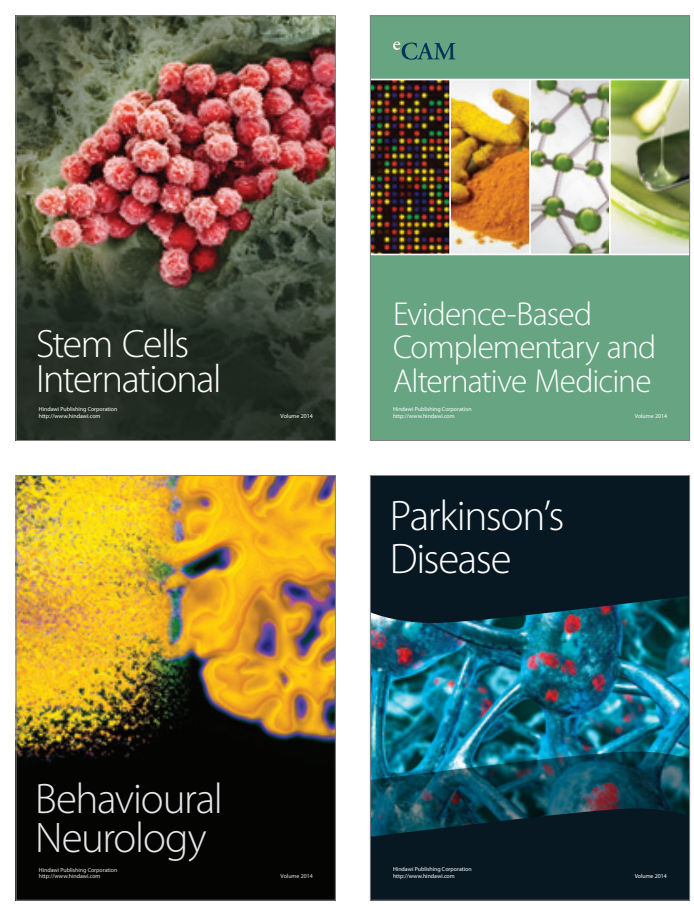

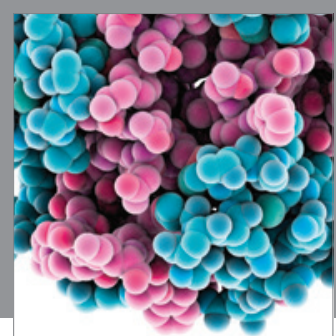

Journal of
Diabetes Research

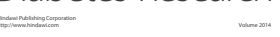

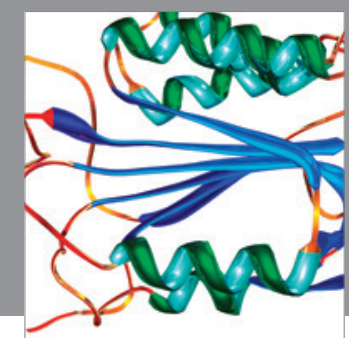

Disease Markers
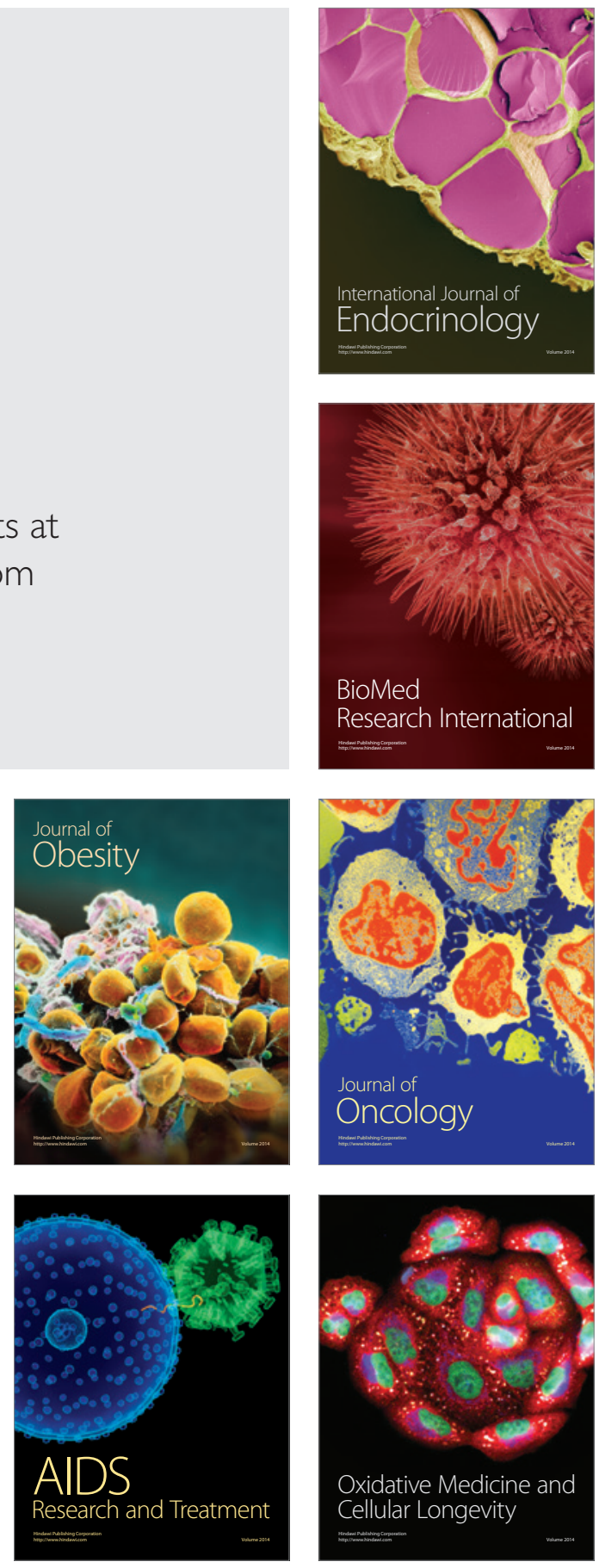